\title{
DOS NOTAS: HISTORIA DE LA SEMÁNTICA; CERVANTES Y EL ESTILO
}

Francisco Abad

UNED

A María Luisa Peces y Emilio Blanco, en su boda.

I. Para la historia de la semántica en españa

En 1914

Alguna vez se han apuntado datos para trazar la historia de la Semántica en el ámbito de la cultura española e hispanoamericana; cuando se haga esa historia no deben olvidarse al menos cuatro publicaciones de García de Diego que no vamos a glosar ahora en todo su contenido, pero sobre las que queremos llamar la atención.

Vicente García de Diego publica en 1914 unos Elementos de Gramática histórica castellana (Burgos, Tipograffa «El Monte Carmelo») cuyo título resulta ya de por sí modesto: estamos ante más de trescientas páginas de formato amplio y densa tipografía. Es una obra raramente citada pero en la que se encuentra una parte de «Semántica» que consta a su vez de dos capitulillos.

La Semántica - define nuestro autor- «estudia la significación de las palabras; su clasificación por las ideas que representan y las alteraciones ideológicas que las palabras sufren», y así en efecto los aludidos dos pequeños capítulos aparecen dedicados a la clasificación y a las alteraciones ideológicas de las voces. La clasificación general de las palabras permite hablar de palabras sinónimas, homónimas, primitivas, etc., mientras en una clasificación 
particular estaremos ante las «partes de la oración»: «Por su significación concreta - expone García de Diego- las palabras se dividen en categorías gramaticales, llamadas partes de la oración: estas son ocho, sustantivo, adjetivo calificativo, determinativo [posesivos, pronombre,...], verbo, adverbio, preposición, conjunción e interjección».

Se nos forma por tanto un cuadro con dos ejes o entradas y según el cual se ordenan los vocablos de la lengua, a saber: la entrada de la clase general de las palabras (sinónimas, etc.), y la clase de su categoría gramatical; en un punto con relación a estos dos ejes se encuentra cada vocablo del español.

En fin García de Diego aborda ahora las «alteraciones ideológicas de las palabras», y escribe en este sentido que las palabras «se alteran y evolucionan en su significado. Estas alteraciones pueden ser: cambios internos de significado, cambios de accidente, cambios de clase y cambios de categoría gramatical». Cambios «de clase» son los que se producen al tomar los propios como apelativos, los apelativos como propios, etc.

\section{La *Gramática castellana»}

Cuatro años más tarde, en 1919, el mismo don Vicente García de Diego publica su Manual de Gramática castellana (Madrid, Tip. de la Rev. de Archivos), obra que asimismo presenta un apartado propio de «Semántica»; tal apartado responde en líneas generales y muchas veces en la literalidad exacta a lo que el autor había escrito en sus anteriores Elementos de Gramática histórica..., aunque cabe notar alguna novedad.

Entre la fecha de los dos libros de García de Diego había publicado el suyo el Padre Restrepo, y don Vicente se hace eco de él al decir ahora en 1919: «La Semántica estudia la significación de las palabras... La significación es el alma de las palabras, que no son tales más que cuando sus elementos fonéticos representan una idea». No hace falta recordar que la obra del P. Félix Restrepo se titulaba y subtitulaba Diseño de Semántica general. El alma de las palabras.

Pero por ejemplo dice también nuestro autor en el Manual...: «Se llama semasiología el cambio de sentido sin sustitución de objeto, como casa, primero "choza"». He aquí un empleo privativo del término «semasiología» que se registra en García de Diego.

\section{Léxico patrimonial y provincialismos}

En tercer término deseamos subrayar un artículo de nuestro autor aparecido en Revista de Occidente, n. ${ }^{\circ}$ XXXVII, 1926: «El léxico español. Su 
riqueza». Este mismo año 1926 es el de ingreso de García de Diego en la Real Academia, y su discurso Problemas etimológicos asimismo estaba planteado teniendo en cuenta lo semántico. Proponía en efecto don Vicente que la «etimología comparativa idealista» refiere distintas modificaciones de forma «a los contactos ideales que ciertas palabras han sufrido por pertenecer a un mismo grupo semántico», y que así toda fórmula etimológica ha de incluir «expresiones complejas en que se retrate el complicado influjo ideal».

El artículo mencionado de «Revista de Occidente» no trata de cuestiones propiamente semánticas sino de léxico; García de Diego estima entonces que sumado el Diccionario oficial y el caudal hablado no recogido «nuestra lengua constaría de cien mil palabras», lo cual supone gran riqueza de vocabulario.

No obstante ha de tenerse presente que el léxico español se compone tanto del «estrato genuinamente castellano» como de «las ruinas de dialectos extraños»: así entendido «si las cien mil palabras que aproximadamente suman el diccionario oficial y los provincialismos no recogidos son legítima riqueza del castellano, esta lengua sería enormemente rica». Nuestro autor tiene como se sabe una clara concepción dialectal del idioma, y por ello tiene presentes todos los dialectalismos de la lengua.

En fin García de Diego restringe en parte la que él mismo ha reconocido enorme riqueza léxica del español, pues no debe importar sólo lo que de algún modo se usa sino - según sus palabras- «lo que es lícito usar dentro de ciertas normas», esto es, dentro de «la norma académica».

Creemos en definitiva que una posible Historia de los análisis semánticos y léxicos de la lengua española no puede desconocer en justicia las sucesivas aportaciones de Vicente García de Diego, a cuatro de las cuales hemos hecho referencia ahora.

II. Lucas Gracián Dantisco y Cervantes: los ideales de lengua y estilo

\section{Los Gracián}

Lucas Gracián Dantisco, el autor del Galateo español, nació en Valladolid en el otoño de 1543, miembro de una familia de abolengo cristiano y que participó en la vida civil y religiosa española; murió el 8 de julio de $1587^{1}$. Lucas era hermano de Antonio Gracián y de Fr. Gerónimo Gracián,

1 Vid. para todo esto Margherita Morreale, ed., Galateo español, Madrid, CSIC, 1968: «Estudio preliminar*. 
quien escribiría las Diez lamentaciones del miserable estado de los ateístas de nuestros tiempos.

De Lucas ha podido decirse que use crió en un ambiente de erudición puesta al servicio de la monarquía, y en efecto fue designado sucesor del primogénito Antonio en la tarea de kintitular e inbentariar los libros del monesterio de San Lorenço el Real "². Además fue censor de libros, y en 1584 -en Madrid- firmb el «priuilegio y licencia» de «los seys libros de Galatea» cervantinos, o sea, de La Galatea de Cervantes.

Uno de los hermanos Gracián era pues Lucas, quien en el Galateo español adaptó el «Trattato» de Giovanni Della Casa divulgado con el nombre simplificado de «Galateo»; este *Trattato...» fue escrito por su autor entre 1551 y 1555 y quedó publicado en $1558^{3}$.

\section{Teóricos conocidos por Cervantes}

Como bien se sabe Edward C. Riley se ha ocupado de Cervantes y la teoría literaria de su tiempo, y ha notado una vez más la incidencia que en $\mathrm{Mi}$ guel de Cervantes tuvo Alonso López Pinciano; igualmente advierte en él la huella de Juan Huarte de San Juan y la de Lucas Gracián, «cuyos comentarios sobre el estilo - escribe- muestran cierto parecido verbal» con los cervanti$n^{4}{ }^{4}$. En orden aproximado de relevancia el escritor alcalaíno se corresponde con Lopez Pinciano, Luis Alfonso de Carvallo, Huarte o Gracián, tal como lo estima Riley5; por supuesto se dan también autores italianos, y en definitiva parece que ocurrió que «la obra del Pinciano pudo llevar a Cervantes al conocimiento de otros tratadistas ...Pudo también ampliar sus lecturas de teoría épica especialmente para escribir el Persiles, novela que le exigio leer gran cantidad de libros» ${ }^{6}$.

La crítica estima -podemos decirlo con palabras de Francisco Márquez Villanueva que representan también a las de otros autores-, que «el conocimiento del popularísimo Galateo por parte de Cervantes no puede ser puesto en dudas ${ }^{7}$; tenemos pues un antecedente inmediato que dejo su impronta en el novelista y que contribuyó a inducir su conciencia idiomática.

2 Ibid.

3 Ibid: pp. 1-3.

4 E.C. Riley, Teoria de la novela en Cervantes, trad. cast., Madrid, Taurus, 1966, pp. 15 ss.

5 Ibid., p. 29.

6 ibid., p. 34.

' F. Márquez Villanueva, Personajes y temas del \&Quijote», Madrid, Taurus, 1975, p. 137n. 


\section{Romance y latín}

La cuestión de la latinidad de Miguel de Cervantes permanece dudosa; Amezúa se inclina por concluir que de la misma manera que otros ingenios de su tiempo, Cervantes «tuvo un mediano conocimiento de la lengua del Lacio aprendido en sus años escolares, aunque sin llegar a dominarla por entero» ${ }^{8}$. De hecho en el Quijote proclamó cómo

$$
\begin{aligned}
& \text {...al cielo no le plu- } \\
& \text { que salieses tan ladi- } \\
& \text { como el negro Juan Lati- }
\end{aligned}
$$

Juan Latino era sobresaliente latinista, hijo de una esclava negra del duque de Sesa?.

En el mismo «Prologo» de la novela Cervantes se ha burlado de la pedanterfa latinizante, cuando hace decir a su amigo: «En lo de citar en las márgenes los libros y autores de donde sacáredes las sentencias y dichos que pusiéredes en vuestra historia, no hay más sino hacer de manera que venga a pelo, algunas sentencias o latines que vos sepais de memoria, o a lo menos que os cuesten poco trabajo el buscalle... Y con estos latinicos y otros tales os tendrán siquiera por gramático, que el serlo no es de poca honra y provecho el día de hoy ${ }^{10}$.

En efecto hay burla de la falsa erudición entre otras cosas porque en el contexto se atribuye a Catón lo que es de Ovidio.

Ángel Rosenblat estima asimismo que Cervantes extrema su burla en este pasaje de la carta de don Quijote al gobernador Sancho: «Un negocio se me ha ofrecido que creo que me ha de poner en desgracia destos señores; pero aunque se me da mucho no se me da nada, pues en fin en fin tengo de cumplir antes con mi profesión que con su gusto, conforme a lo que suele decirse: amicus Plato, sed magis amica veritas. Dígote este latín porque me doy a entender que después que eres gobernador lo habrás aprendido" ${ }^{11}$.

Encontramos por tanto que Cervantes sabía su latín, aunque se burlaba de la falsa erudición y escribió también una defensa de la lengua vulgar: estamos ante un conocido pasaje de la «Segunda parte».

- Agustín G. de Amezúa y Mayo, Cervantes creador de la novela corta española, Madrid, CSIC, 1982 (reimpresión), I, p. 49.

- Miguel de Cervantes, El ingenioso hidalgo don Quijote de la Mancha, ed. de Luis Andres Murillo, I, Madrid, Castalia, $1985^{3}$, p. 61.

${ }^{10}$ Ibid., pp. 54-55.

" El ingenioso hidalgo..., II, Madrid, 19833, pp. 429-430; A. Rosenblat, La lengua del «Quijotex, Madrid, Gredos, 1971, pp. 14-20. Hemos tenido en cuenta todos los textos sobre los que llama la atención Rosenblat, si bien volviéndolos a examinar por nuestra cuenta. 
Y a lo que decís, señor -proclama don Quijote— que vuestro hijo no estima mucho la poesía de romance, doyme a entender que no anda muy acertado en ello y la razón es ésta: el grande Homero no escribio en latún porque era griego, ni Virgilio no escribió en griego porque era latino. En resolución todos los poetas antiguos escribieron en la lengua que mamaron en la leche, y no fueron a buscar las estranjeras para declarar la alteza de sus conceptos. Y siendo esto así, razon sería se estendiese esta costumbre por todas las naciones, y que no se desestimase el poeta alemán porque escribe en su lengua, ni el castellano, ni aún el vizcaíno que escribe en la suya ${ }^{12}$.

La lengua originaria queda exaltada: se trata de la lengua propia del lugar de nacimiento, y cualquiera de ellas es válida para manifestar los altos conceptos; a «la dulce lengua de mi nación» se refiere un personaje de Los trabajos de Persiles y Sigismunda, quien manifiesta además que al oírla tiene *ya por cierto el fin de [sus] desgracias» ${ }^{13}$.

En el Coloquio de los perros hace alusión sin embargo Cervantes a las clases de latinidad: «Este mercader, pues - relata Berganza- tenía dos hijos, el uno de doce y el otro de hasta catorce años, los cuales estudiaban gramática en el estudio de la Compañía de Jesús [...] Era tiempo de invierno, cuando campean en Sevilla los molletes y mantequillas, de quien era tan bien servido que más de dos Antonios se empeñaron o vendieron para que yo almorzase* ${ }^{14}$. Los «Antonios* eran los ejemplares de las Introductiones latinae de Nebrija, empleadas como libro de texto.

En este mismo Coloquio... Miguel hace burla por boca de Berganza y Cipión de quienes entremezclan romance y latín en la conversación, y de quienes son necios a pesar de hablar en latín:

BERGANZA. [...] Hay algunos romancistas que en las conversaciones disparan de cuando en cuando con algún latín breve y compendioso, dando a entender a los que no lo entienden que son grandes latinos, y apenas saben declinar un nombre y conjugar un verbo.

CIPION. Por menor daño tengo ése que el que hacen los que verdaderamente saben latín, de los cuales hay algunos tan imprudentes que hablando con un zapatero o con un sastre arrojan latines como agua.

\footnotetext{
12 El ingenioso..., I, pp. 155-156. 107.

13 Miguel de Cervantes, Los trabajos.., ed. de J.B. Avalle-Arce, Madrid, Castalia, 1990, p.

14 Miguel de Cervantes, «Coloquio...», J.B. Avalle-Arce, ed., Novelas Ejemplares, Madrid, Castalia, III, 19903. pp. 239-322: pp. 261 y 265.
} 
BERGANZA. De eso podremos inferir que tanto peca el que dice latines delante de quien los ignora como el que los dice ignorándolos. CIPIÓN. Pues otra cosa puedes advertir, y es que hay algunos que no les excusa el ser latinos de ser asnos.

BERGANZA. Pues ¿quién lo duda? La razón está clara, pues cuando en tiempo de los romanos hablaban todos latín como lengua materna suya, algún majadero habría entre ellos a quien no excusarfa el hablar latín de ser necio.

CIPIÓN. Para saber callar en romance y hablar en latín discreción es menester, hermano Berganza.

BERGANZA. Así es, porque también se puede decir una necedad en latín como en romance, y yo he visto letrados tontos, y gramáticos pesados, y romancistas vareteados con sus listas de latin, que con mucha facilidad pueden enfadar al mundo no una, sino muchas veces's.

Por un lado pues Cervantes se sonríe y hace chanza de quienes imprudentemente entremezclan latín y lengua vulgar en la conversación, y por otro advierte que el saber latín no garantiza que no se digan necedades; en ambos casos se hace necesario el «buen seso»; «discreción» es en efecto - señalaba Covarrubias - «la cosa dicha o hecha con buen sesom ${ }^{16}$. No hablar latín no importa: puede uno expresarse en su lengua materna siempre que lo haga con discreción.

El entremezclar en el habla expresiones latinas quedó ya señalado como afectación por Lucas Gracián Dantisco, quien manifestaba a la letra: «Mayormente se deve cada qual guardar de entremeter palabras latinas y extraordinarias adonde no hay latinos ni quien las entienda, porque en este yerro caen muchos que con un poco de gramática que estudiaron, meten vocablos latinos en quanto hablan, tan fuera de propósito que en la propiedad de nuestro romance discordan y suenan tan mal que no hay quien los aguardex ${ }^{17}$. Esta forma de afectación es la misma que censura Cervantes, quien además manifiesta su estima del idioma romance y pide que en el uso de la lengua se observe en todo caso la discreción; una manera de falta a la discreción es el discurso afectado por la mezcla en él de expresiones latinas.

En último término importa el romance y en él importa el uso: sobre la lengua -proclamó don Quijote- «tiene poder el vulgo y el uso» ${ }^{18}$; el uso hace

15 Ibid., pp. 267-268.

16 Sebastián de Covarrubias, Tesoro de la lengua castellana o española, ed. por Martín de Riquer, Barcelona, Horta, 1943, p. 475b.

17 Galateo espariol, p. 141.

18 El ingenioso..., II, p. 361. 
las lenguas y hace que nos entendamos en ellas, las nivela o estandariza (diríamos más técnicamente) y las hace instrumentos útiles.

\section{La conciencia de estilo}

Cervantes mantuvo cómo además de por la invención, debían los libros procurar el contento por su «lenguaje» o elocución; a don Diego de Miranda hemos visto que le ha postulado don Quijote que los poetas escriban «en la lengua que mamaron en la leche», y es don Diego de Miranda quien poco antes manifestaba a su vez: «Tengo hasta seis docenas de libros... Hojeo más los que son profanos que los devotos como sean de honesto entretenimiento, que deleiten con el lenguaje y admiren y suspendan con la invención, puesto que déstos hay muy pocos en España» ${ }^{19}$. En el transcurrir de la serie literaria Miguel de Cervantes estima el lenguaje que deleita y lo echa en falta: hay muy pocos libros que contenten con la elocución y admiren con su invención.

El capítulo catorce del Tercero Libro de Los trabajos de Persiles... se inicia con estas palabras: "La historia, la poesía y la pintura simbolizan entre sí y se parecen tanto, que cuando escribes historia pintas, y cuando pintas compones. No siempre va en un mismo peso la historia, ni la pintura pinta cosas grandes y magníficas, ni la poesía conversa siempre por los cielos. Bajezas admite la historia; la pintura, hierbas y retamas en sus cuadros; y la poesía, tal vez se realza cantando cosas humildes» ${ }^{20}$. A Cervantes le importaba el estilo, y justamente - vemos - la variedad en el estilo, las diferencias y variabilidades conseguidas en el mismo; Riley interpreta que con el presente pasaje el autor expresa su repugnancia ante el estilo absolutamente uniforme ${ }^{2 !}$.

El acierto cervantino de mayor originalidad (subraya este mismo estudioso) consistio en «el uso de estilos contrapuestos en el Quijote»22; efectivamente la novela recoge la complejidad de lo real todo, las «cosas humildes»: estamos ante el realismo barroco de lo complejo en el que la poesía no «conversa siempre por los cielos ${ }^{23}$.

19 Ibid., p. 153.

20 Los trabajos..., p. 371.

21 Teoría de la novela..., p. 232.

22 Ibid., p. 220.

${ }^{23}$ Cfr. Francisco Abad, «El realismo de lo complejo en Cervantes», Estudios Filológicos, Universidad de Valladolid, 1980, pp. 121 ss. 


\section{Discreción y propiedad}

El ideal lingǘstico cervantino es el de la discreción, según quedó proclamado en un pasaje bien conocido:

...Sí, que ¡válgame Dios! no hay para qué obligar al sayagués a que hable como el toledano, y toledanos puede haber que no las corten en el aire en esto del hablar polido.

-Así es -dijo el licenciado-; porque no pueden hablar tan bien los que se crían en las Tenerías y en Zocodover como los que se pasean casi todo el día por el claustro de la Iglesia Mayor, y todos son toledanos. El lenguaje puro, el propio, el elegante y claro, está en los discretos cortesanos aunque hayan nacido en Majadahonda: dije discretos porque hay muchos que no lo son, y la discreción es la gramática del buen lenguaje, que se acompaña con el uso's.

El criterio del buen idioma no está por tanto en el prestigio local que tenga, en su raigambre geográfica, sino en el arte de la discreción; el arte de hablar está en la discreción dentro del uso cortesano, o sea, en la discreción dentro del uso culto. «Discreto» - establecía Covarrubias- es «el hombre cuerdo y de buen seso, que sabe ponderar las cosas y dar a cada una su lugarn25; naturalmente la discreción es tener buen seso, como hemos visto ya.

Un modelo de lengua culta, que se mueve dentro de lo usual, y discreta en la construcción es lo que postula Cervantes; en ese modelo reside el arte o gramática del buen lenguaje. Discreción es oportunidad, y la oportunidad expresiva en lo usual culto resulta el criterio de buen idioma.

Igualmente la lengua ha de tener propiedad: $\ll$ Habla con propiedad - dice Berganza a Cipión-, que no se llaman colas las del pulpo», sino rabos ${ }^{26}$; además Cervantes pondera que los cuentos posean «la propiedad del lenguaje en cualquiera cosa que se digas ${ }^{27}$. La propiedad era requisito elocutivo que había sido pedido en el Galateo español:

Hase de guardar... en todo lo... que se habla la propriedad y pureza de los vocablos, sin apartarse del común uso y verdadero romance dellos [...] Digo pues que deven ser las palabras, lo más que ser puedan, apropriadas y fáciles, según se usan en la tierra donde estuvieres [...]

24 El ingenioso..., II, p. 182.

25 Tesoro..., p. 475 b.

26 «Coloquio de los perros», ed. cit., p. 269.

27 Los trabajos de Persiles..., pp. 322-323. 
También deven ser las palabras lo más apropriadas que ser puedan a lo que se quiere mostrar por ellas, y menos comunes a otras cosas y significados ${ }^{28}$.

Lo «más proprio» debe preferirse pues a lo menos, aunque esto último sea inteligible; así se manifiesta Lucas Gracián, y Cervantes adopta por igual el criterio de la propiedad significativa de las palabras.

\section{Sobre la afectación}

Miguel de Cervantes «se ensaña con la afectación», ha indicado la crítica ${ }^{29}$, y así ocurre efectivamente; al inicio del Quijote se está refiriendo a los libros de caballerías que compraba el héroe novelesco y se expresa: «De todos ningunos le parecían tan bien como los que compuso el famoso Feliciano de Silva, porque la claridad de su prosa y aquellas entricadas razones suyas le parecían de perlas, y más cuando llegaba a leer aquellos requiebros y cartas de desafíos donde en muchas partes hallaba escrito: La razón de la sinrazón que a mi razón se hace, de tal manera mi razón enflaquece, que con razón me quejo de la vuestra fermosura... Con estas razones perdía el pobre caballero el juicio, y desvelábase por entenderlas y desentrañarles el sentido, que no se lo sacara ni las entendiera el mesmo Aristóteles si resucitara para sólo ello» ${ }^{30}$. Aquí no hay discreción u oportunidad expresiva, ni propiedad de un sentido o significado que ni Aristóteles podría desentrañarlo, ni llaneza sino afectación, y frente a todo ello estaba Cervantes. Incluso el remedo con la $f$ - de la lengua antigua (fermosura) supone un rechazo del estilo afectado ${ }^{31}$.

En un segunddo pasaje asimismo bien conocido el novelista nos relata: «Aquí alzó otra vez la voz maese Pedro y dijo: - Llaneza, muchacho; no te encumbres, que toda afectación es mala ${ }^{32}$; la «afectación» por tanto queda excluida del buen estilo, al igual que Lucas Gracián se había manifestado en contra de ella: «Las afectaciones y demasías (escribio) se deven evitar en los traxes y cerimonias y mucho más en las palabras ${ }^{33}$.

\footnotetext{
28 Galateo..., pp. 164-166.

29 A. Rosenblat, La lengua.... p. 20.

${ }^{30}$ El ingenioso hidalgo..., I, p. 72.

${ }^{31}$ Cfr. A. Rosenblat, La lengua..., pp. 26-32.

${ }^{32}$ El ingenioso hidalgo..., II, p. 243.

33 Galateo..., p. 141.
} 
Lucas Gracián Dantisco insistió en ello: se han de uescusar - proclamaba- palabras impropias y afectadas ${ }^{34}$, y ha de procurarse «antes llaneza que no artificion" ${ }^{35}$; existe incluso en el Galateo español un parrafo que parece estar en el origen del pasaje en que Cervantes alude a Feliciano de Silva: «Han de ser pues las palabras bien ordenadas según lo que es uso y costumbre, y no atadas ni rebueltas acá y allá, ni entricadas como algunos usan por gallardía, como es dezir: "Mi lumbre se deslumbra en vuestra lumbre"»36.

Lucas Gracián y con él Miguel de Cervantes pide llaneza y no artificio, y ambos hacen mofa de las razones y palabras «entricadas»; «dezimos estar un negocio entricado —anotaba a su vez Covarrubias-, conviene a saber enredado y emarañado, con muchas dificultades ${ }^{37}$.

\section{Honestidad verbal}

Tampoco las palabras pueden dejar de ser honestas en el discurso, y así lo había proclamado también Gracián:

Procure el gentil hombre -escribe - que se pone a contar algún cuento o fábula, que sea tal que no tenga palabras deshonestas, ni cosas suzias ni tan puercas que puedan causar asco a quien le oye, pues se puede dezir por rodeos y términos limpios y honestos, sin nombrar claramente cosas semejantes [...] Deve tambien el discreto gentilhombre procurar que sus palabras sean castas y honestas y biensonantes; quiero dezir, que tengan buen sonido, buena voz y buena significación, porque hay algunas palabras que lo son en el significado y no en el sonido, como quando dizen: «fuése reculando atrás» por dezir: «fuese retrayendow ${ }^{38}$.

De nuevo vamos a ver a Cervantes mantener la misma idea, y otra vez en el coloquio entre Cipión y Breganza; las palabras del novelista son asimismo bien conocidas: «Ese es el error que tuvo el que dijo que no era torpedad ni vicio nombrar las cosas por sus propios nombres, como si fuese mejor ya que sea forzoso nombrarlas, decirlas por circunloquios y rodeos que

\footnotetext{
34 Ibid., p. 143.

39 Ibid., p. 164.

36 Ibid., p. 169.

37 Tesoro..., p. 526a.

38 Galateo espariol, pp. 155 y 167.
} 
templen la asquerosidad que causa el oírlas por sus mismos nombres». Las honestas palabras - concluye la proclama cervantina- dan indicio de la honestidad de quien las profiere ${ }^{39}$.

Al igual que la propiedad en el significado se ha de procurar la honestidad en los vocablos; Miguel de Cervantes sigue de cerca incluso en las palabras a Lucas Gracián.

\section{Conclusiones}

1. Lucas Gracián Dantisco y también su hermano Fray Gerónimo Gracián -l autor de las Diez lamentaciones del miserable estado de los ateístas de nuestros tiempos-, pertenecieron a una familia notoria en la vida civil y religiosa española del Quinientos.

2. En el Galateo español (1593) Lucas Gracián adaptó un «Trattato nel quale... de Mons. Giovanni Della Casa publicado en 1558.

3. Gracián se encuentra entre los tratadistas que parecen haber incidido en la conciencia literaria y en la obra de Cervantes, junto a Alonso López Pinciano y otros autores más.

4. Cervantes debi6 de poseer un conocimiento mediano del latín, pero se burló de la afectación latinizante y manifestó cómo el saber ese idioma no garantizaba la discreción ni el no ser necio.

5. Miguel defendió que cada autor escribiese en su lengua natural.

6. Cervantes echa de menos en la serie literaria castellana obras «que deleiten con el lenguaje», un lenguaje que se ocupe asimismo «de cosas humildes» y que por tanto este hecho de estilos entremezclados.

7. Criterio de buen lenguaje es la discreción, discreción dentro del uso culto o cortesano; el buen idioma es el que posee oportunidad expresiva dentro de lo que es usual y culto.

8. La lengua ha de poseer también propiedad significativa en sus vocablos.

9. Se ha de huir de la afectación, que siempre resulta mala.

10. Asimismo se ha de templar la «asquerosidad» que en el sonido o en la significación puedan tener las palabras.

11. Cervantes coincide por tanto con Lucas Gracián Dantisco en varios de los rasgos de su conciencia idiomática:

a) rechazo de la afectación latinizante y de toda afectación

39 «Coloquio de los perros», p. 269. 
b) los autores han de atenerse al uso establecido y a la propiedad significativa de las palabras

c) las palabras asimismo han de resultar honestas y biensonantes.

\section{Juan de Valdés, Lucas Gracián, Cervantes}

Creemos que el tratado de Lucas Gracián Dantisco constituyó un estímulo inmediatamente actuante en la conciencia de escritor de Miguel de Cervantes; se ha dicho bastantes veces que con anterioridad Juan de Valdés había manifestado varias apreciaciones análogas, pero lo que conoció Cervantes fue el texto de Lucas. Existe una analogía entre los tres autores, pero fue Gracián el que incidió en Cervantes.

En efecto Valdés estableció que todos los hombres estamos obligados a ilustrar y enriquecer la lengua que nos es natural ${ }^{40}$, e incluso como Cervantes se quejó de que «la lengua castellana nunca ha tenido quien escriva en ella con tanto cuidado y miramiento quanto sería menester» ${ }^{41}$. También Valdés proclamaba la «autoridad» que tiene «el uso» ${ }^{42}$, y que «en ninguna lengua está bien el afetación» ${ }^{43}$; de la misma manera pidio el empleo de vocablos que «sinifiquen bien lo que quiero dezirs ${ }^{44}$.

Tenemos por consiguiente varios motivos de analogía entre Juan de Valdés y Cervantes, y ello nos autoriza a decir que participan de una misma conciencia de lengua y estilo en varios de sus aspectos; en la serie literaria española quien antecede inmediatamente a Cervantes es sin embargo Lucas Gracián, y él debió de ser quien estimuló el pensamiento del alcalaíno, el que le ayud6 a encontrarse a sí mismo. No hace falta recordar que el texto valdesino no sería editado sino con posterioridad..$^{(*)}$ 1969, p. 44

40 Juan de Valdés, Diálogo de la lengua, ed. de Juan M. Lope Blanch, Madrid, Castalia,

41 Ibid.

42 Ibid., p. 107.

${ }^{43}$ Ibid., p. 154.

4 Ibid.

(*) Las presentes páginas cervantinas fueron presentadas como comunicación en el Primer Congreso Internacional de la Asociación de Cervantistas, celebrado en Almagro en 1991; aunque hace bastante tiempo se corrigieron las pruebas de las Actas, tenemos entendido que no es fácil salgan de inmediato, y de hecho hemos visto que distintos autores han publicado ya su respectivo trabajo. Publicamos nosotros ahora nuestro escrito, si bien con algunos párrafos menos para abreviar. 